\title{
Under Weightiness among Ever-married Non-pregnant Women in Bangladesh: A Population Based Study
}

\author{
Md. Shafiur Rahman ${ }^{1,2}$, Md. Nazrul Islam Mondal ${ }^{2, *}$, Md. Rafiqul Islam², Kazi Mohiuddin Ahmed ${ }^{3}$, \\ Md. Reazul Karim ${ }^{4}$, Md. Shamsher Alam ${ }^{5}$ \\ ${ }^{1}$ Department of Public Health, First Capital University of Bangladesh, Bangladesh \\ ${ }^{2}$ Department of Population Science and Human Resource Development, University of Rajshahi, Bangladesh \\ ${ }^{3}$ Department of Community Medicine, Pabna Medical College, Bangladesh \\ ${ }^{4}$ Development Association for Self-reliance Communication and Health, Lutheran Mission Complex, Bangladesh \\ ${ }^{5}$ Department of Human Ecology, Faculty of Ecology, Peoples' Friendship University of Russia, Russia
}

Copyright (C) 2015 Horizon Research Publishing All rights reserved.

\begin{abstract}
The increasing prevalence of under weightiness among young women is a growing public health concern. This paper identified the determinant factors of under weightiness among non-pregnant ever-married women in Bangladesh. Data and necessary information of 16,206 non-pregnant ever-married women were extracted from the Bangladesh Demographic and Health Survey 2011. The chi-square test and binary logistic regression analysis were used as the statistical tools to analyze the data. The results revealed that the women are found underweight around two times more $(15.4 \%$ in urban, and $28 \%$ in rural) in the rural areas than that of urban areas in Bangladesh. Almost all the factors are found statistically significantly associated with underweight for both urban and rural areas. The binary logistic regression model identified the higher risk of being underweight in the younger age group (15-24 years), illiteracy, husband's illiteracy, having more children, poor economic condition, not having exposure to mass media, household food unsecured, and genital discharged women for both urban and rural areas. The under weightiness among non-pregnant ever-married women for both urban and rural areas are prevalent. Therefore, there is a need for public health programs related to nutrition that are able to address both the areas simultaneously.
\end{abstract}

Keywords Ever-married Non-pregnant women, Urban-rural Differentials, Body Mass Index, Under-weightiness

\section{Introduction}

Ever married women are considered the persons who have been married at least once in their lives. Underweight is a term describing a human whose body weight is considered too low to be healthy. Poor nutrition in adults can result in underweight. Underweight might be secondary or symptomatic of an underlying disease. Unexplained weight loss may require professional medical diagnosis. Severely underweight individuals may have poor physical stamina and a weak immune system, leaving them to open to infection. People who are malnutrition underweight raise special concerns, as not only gross caloric intake may be inadequate, but also intake and absorption of other vital nutrients, especially essential amino acids and micro-nutrients such as vitamins and minerals. Body mass index (BMI) is an indicator of nutritional status [1]. The extreme categories of BMI, viz. underweight, overweight and obese, as compared to the normal BMI, are associated with a variety of adverse health outcomes [2-4]. An increasing trend of underweight is found to be common in many developing countries [5], including Bangladesh [6]. The underweight is a particular issue for developing countries as it is the first and fourth leading cause of death and disability in the high-mortality and low-mortality developing countries, respectively [4]. Continued economic development, rapid urbanization specifically for the developing countries, globalization of food production and changes in dietary patterns are some of the important determinant factors of extreme categories of BMI $[5,7]$.

Being underweight is usually the result of deficit energy consumption is considered as a public health problem. Under nutrition remains a devastating problem in many developing countries over 815 million people and causing more than one-half of all child deaths [8]. The underweight is associated with preterm birth and low birth weight, malnourished children, and poor psychological health, including high mortality [9-12]. The conditions being underweight or overweight can exist in close proximity, such as in the same community and same household [1]. Such conditions could be linked to different environmental, behavioral and individual risk factors [13]. The BMI depends on many factors like age, education, occupation, 
household economic status, food habits and sedentary lifestyles [6,14-15]. The underweight are susceptible to poor maternal and infant health as well as childhood growth problems and compromised mental development [16]. The higher level of malnutrition among women and female children compared to men and male children in Bangladesh $[6,14]$ may be associated with a higher level of gender discrimination that exists in all sectors of Bangladesh. Gender discrimination also exists in other South Asian countries [17]. The reproductive health rights of women are also desecrated in Bangladesh [18]. Different forms of discriminations usually start from early childhood and continue throughout their lives [19]. The independent impact of women malnutrition (e.g., due to food and healthcare discrimination) on their babies and children is also remarkable. Generally, gender discrimination, gender roles and social norms can characterize a malnourished mother by a cycle of early marriage and childbearing, the closer birth spacing, and under-nutrition. This intergenerational influence (i.e. from mother to baby) of childhood nutrition suggests the necessity of having a better nutritional status in early childhood to improve the child health in the next generation [20]. In women, being grossly underweight may result in amenorrhea, infertility and possible complications during pregnancy. Being underweight causes increased mortality at rates comparable to that seen in morbidly obese people. Some other factors, such as the mother's illiteracy, low household income, higher number of children, less access to the mass media, less supplementation of diets, unhygienic water supply and sanitation, are also associated with the chronic and severe malnutrition of children in Bangladesh [21-22]. Therefore, the main purposes of this study are to investigate the urban-rural differentials and extract the associated socioeconomic and health characteristics of underweight among the ever-married non-pregnant women in Bangladesh. Hopefully, this study will enrich available information and contribute to develop appropriate interventions for reducing this health burden.

\section{Data and Methods}

\subsection{Source of Data}

The study utilized a representative set of cross-sectional data extracted from the Bangladesh Demographic and Health Survey (BDHS) 2011 [23]. The survey was conducted under the authority of the National Institute of Population Research and Training (NIPORT) under the Ministry of Health and Family Welfare (MOHFW), Bangladesh. The BDHS 2011 was the sixth national level Demographic and Health Survey conducted in Bangladesh. Previously, BDHS were carried out in 1993-94, 1996-97, 1999-2000, 2003-04, and 2007-08. The BDHS 2011 was carried out to provide up-to-date information on fertility and childhood mortality levels; fertility preferences; awareness, approval, and use of family planning methods; maternal and child health; knowledge and attitudes toward sexually transmitted infections; community-level data on accessibility and availability of health and family planning services; and prevalence of non-communicable diseases. It was designed to produce representative results for the country as a whole, for the urban and the rural areas separately, and for each of the seven administrative divisions of the country. All ever-married women aged 12-49 years who were usual members of the selected households and those who spent the night before the survey in the selected households were eligible to interview in the survey. The details of the sampling survey design, survey instruments and quality control are reported elsewhere [23]. However, a brief description is given in the following subsections.

\subsection{Sampling}

The sample for the BDHS 2011 is nationally representative and covers the entire population residing in non-institutional dwelling units in the country. The survey used the list of enumeration areas (EAs) prepared for the 2011 Population and Housing Census provided by the Bangladesh Bureau of Statistics as a sampling frame. The primary sampling unit for the survey is an EA that was created to have an average of about 120 households. Administratively, Bangladesh has seven administrative divisions: Barisal, Chittagong, Dhaka, Khulna, Rajshahi, Rangpur, and Sylhet. Each division is subdivided into zilas (districts), and each zila into upazilas (sub-district). Each urban area in an upazila is divided into wards, and into mohallas (an area of a town or village; a community) within a ward. A rural area in the upazila is divided into union parishads (UP) (the smallest rural administrative and local government units) and mouzas (a specific land area within which there may be one or more settlements) within a UP. These divisions allow the country as a whole to be easily separated into rural and urban areas. The samples were stratified and selected in two stages. Each division was stratified into urban and rural areas. The urban areas of each division were further stratified into two strata: city corporations and other than city corporations. Because Rangpur Division had no city corporations, a total of 20 sampling strata were created. Samples of EAs were selected independently in each stratum in two stages. In the first stage, 600 EAs were selected with probability proportional to the EA size, with 207 clusters in urban areas and 393 in rural areas. The survey was conducted in 18,000 residential households, 6,210 in urban areas and 11,790 in rural areas. A total of 18,222 ever-married women aged 12-49 years were identified in these households of them 17,842 were interviewed (98\% response rate). Data were collected from respondents during July 8, 2011 to December 27, 2011.

\subsection{Sample Size Selection}

Ever-married women were considered them who have been married at least once in their lives although their current 
marital status may not be married. The data are presented in the numerator of each ratio is the sum of the number of persons who are currently married and those who are either divorced, widowed or separated. The denominator is the total number of persons in the corresponding age group. The number of women with unknown marital status is excluded from both numerator and denominator, implying that they are assumed to have the same distribution by marital status as the population that reported that status. The BDHS 2011 measured the height and weight of 17,640 ever-married women of reproductive age (15-49 years) from the total 17,842 interviewed women. For analytical purposes, the data was restricted to ever-married women, who were not pregnant at the time of survey. So, pregnant women were excluded because anthropometric measurements, like body weight, increase rapidly during the pregnancy and indicate both nutritional status of the women and growth of the foetuses, and reduce the specificity of the indicator. Women with unusual BMI values (BMI $<12.0 \mathrm{~kg} / \mathrm{m}^{2}$ and $\mathrm{BMI}>50$ $\mathrm{kg} / \mathrm{m}^{2}$ ) and women with missing information on any covariates were also excluded from the analysis. After excluding pregnant women, women with unusual BMI values, women aged less than 15 years, and women with missing information on the outcome variables and covariates, the final sample size become 16,206.

\subsection{Outcome Variable}

The unit of analysis of the study is underweight. The underweight status was measured from BMI. Anthropometric measurement weight and height is used to calculate BMI. The BMI is a simple index of weight-for-height and an indicator of body composition, which is defined as follows:

$$
B M I=\frac{\text { Weight of the adult in kilogram }}{(\text { Height of the adult in meter })^{2}}
$$

A woman was classified as having underweight if her BMI was $<18.50 \mathrm{~kg} / \mathrm{m}^{2}$ and not underweight for BMI $\geq 18.50$ $\mathrm{kg} / \mathrm{m}^{2}$ [24].

\subsection{Explanatory Variables}

This study used 11 explanatory variables with categories shown in the parenthesis: age in years $(15-24,1 ; 25-34,2$; $35-49,3$ ); education (no education, 1 ; primary, 2; secondary, 3 ; higher, 4); husband's education (no education, 1; primary, 2; secondary, 3; higher, 4); children ever born (CEB) (no child, $1 ; 1-2$ child(ren), 2; >2 children, 3 ); current marital status (living with husband, 1; widowed/divorced/separated, 2); oral contraceptive pill (OCP) use (no, 0 ; yes, 1); currently working (no, 0 ; yes, 1); wealth index (poor, 1 ; middle, 2 ; rich, 3); exposure to mass media (no, 0 ; yes, 1); having household food security (no, 0 ; yes, 1); and genital discharged (no, 0 ; yes, 1).

\subsection{Statistical Analysis}

To examine the relationship between underweight and background characteristics of the women, Chi-square test and binary logistic regression are analysis employed. For statistical analyses, BMI was made a binary response. The bivariate analysis (Chi-square test) was used to find the association between dependent and independent variables. The two binary logistic regression models were fitted for urban and rural areas separately to identify the associated factors of underweight among non-pregnant ever-married women. In logistic regression analysis, underweight $\left(Y_{j}\right.$, $j=1,2)$ was treated as the dependent variable.

In this model, the dependent variable is classified in the following way:

$$
Y_{j}=\left\{\begin{array}{l}
1 ; \text { if the respondent was underweight }\left(\mathrm{BMI}<18.5 \mathrm{~kg} / \mathrm{m}^{2}\right) ; \\
0 ; \text { otherwise. }
\end{array}\right.
$$

In binary logistic regression model, 9 independent variables $\left(X_{i}, i=1,2, \ldots ., 9\right)$, viz., respondents' age $\left(X_{I}\right)$, education $\left(X_{2}\right)$, husband's education $\left(X_{3}\right)$, CEB $\left(X_{4}\right)$, OCP use $\left(X_{5}\right)$, wealth index $\left(X_{6}\right)$, exposure to mass-media $\left(X_{7}\right)$, having household food security $\left(X_{8}\right)$, and genital discharge for the last 12 months $\left(X_{9}\right)$ were entered.

The results of the regression models are presented by odds ratios (OR) with $95 \%$ confidence interval (CI) for easy understanding of the effects of the associated factor. The Statistical Package for Social Sciences version 17.0 (SPSS Inc, Chicago, IL, USA) was used for statistical analysis.

\section{Results}

\subsection{Urban-rural Differentials of Underweight}

A total of 16,206 (5,692 urban and 10,514 rural) ever-married non-pregnant women aged 15-49 years were included in this analysis. The prevalence of underweight according to socio-demographic and health related characteristics are presented in Table 1.

The results indicated that, $15.4 \%$ of urban women, and $28 \%$ of rural women were found underweight. The results indentified that the higher percentage underweighted women were in the younger age groups, illiterate, husband's illiteracy, no child, marital life without husband, currently working, poor economic condition, not having access to mass media, household food insecurity, and genital discharged for both urban and rural areas. In case of OCP use, the higher percentage women were seen in the rural areas. However, the higher percentage of overall prevalence of underweighted among women were seen in the rural area ( $15.4 \%$ in urban, and $28 \%$ in rural). The chi-square test was performed to find the associations between women's age, education, husband's education, CEB, current marital status, OCP use, working status, wealth index, exposure to mass media, household food security, and genital discharge in the last 12 months with underweight. The underweight is statistically significantly associated with all the aforesaid factors except OCP use for the urban women; and except current working status for rural women. 
Table 1. Urban-rural differentials of underweight among ever-married non-pregnant women $(\mathrm{N}=16,206)$

\begin{tabular}{|c|c|c|c|c|c|c|c|c|}
\hline \multirow[t]{3}{*}{ Characteristics } & \multicolumn{4}{|c|}{ Urban } & \multicolumn{4}{|c|}{ Rural } \\
\hline & \multicolumn{3}{|c|}{ Underweight } & \multirow[b]{2}{*}{$\begin{array}{c}\text { Level of } \\
\text { significance }\end{array}$} & \multicolumn{3}{|c|}{ Underweight } & \multirow[b]{2}{*}{$\begin{array}{c}\text { Level of } \\
\text { significance }\end{array}$} \\
\hline & Yes $(\%)$ & No $(\%)$ & Total & & Yes $(\%)$ & No $(\%)$ & Total & \\
\hline \multicolumn{9}{|l|}{ Age } \\
\hline $15-24$ years & $364(23.5)$ & $1187(76.5)$ & 1551 & $* * *$ & $1016(34.0)$ & $1972(66.0)$ & 2988 & $* * *$ \\
\hline 25-34 years & $253(12.8)$ & $1720(87.2)$ & 1973 & & $884(24.5)$ & $2723(75.5)$ & 3607 & \\
\hline $35-49$ years & $260(11.99)$ & $1908(88.01)$ & 2168 & & $1044(26.64)$ & $2875(73.36)$ & 3919 & \\
\hline \multicolumn{9}{|l|}{ Education } \\
\hline No education & $261(23.0)$ & $873(77.0)$ & 1134 & $* * *$ & $1048(32.5)$ & $2178(67.5)$ & 3226 & $* * *$ \\
\hline Primary ${ }^{1}$ & $284(19.1)$ & $1204(80.9)$ & 1488 & & $984(29.4)$ & $2362(70.6)$ & 3346 & \\
\hline Secondary $^{2}$ & $280(12.57)$ & $1948(87.43)$ & 2228 & & $845(24.2)$ & $2645(75.8)$ & 3490 & \\
\hline Higher & $52(6.2)$ & $790(93.8)$ & 842 & & $67(14.82)$ & $385(85.25)$ & 452 & \\
\hline \multicolumn{9}{|l|}{ Husband's Education } \\
\hline No education & $281(24.2)$ & $879(75.8)$ & 1160 & $* * *$ & $1246(34.1)$ & $2408(65.9)$ & 3654 & $* * *$ \\
\hline Primary $^{1}$ & $262(19.8)$ & $1061(80.2)$ & 1323 & & $872(28.9)$ & $2145(71.1)$ & 3017 & \\
\hline Secondary ${ }^{2}$ & $242(13.35)$ & $1571(86.65)$ & 1813 & & $678(23.7)$ & $2181(76.3)$ & 2859 & \\
\hline Higher & $92(6.6)$ & $1304(93.4)$ & 1396 & & $148(15.04)$ & $836(84.96)$ & 984 & \\
\hline \multicolumn{9}{|l|}{ Child Ever Born } \\
\hline No child & $95(18.9)$ & $407(81.1)$ & 502 & $*$ & $256(33.3)$ & $513(66.7)$ & 769 & $* *$ \\
\hline 1-2 child & $428(14.5)$ & $2523(85.5)$ & 2951 & & $1208(26.7)$ & $3318(73.3)$ & 4526 & \\
\hline$>2$ children & $358(15.99)$ & $1881(84.01)$ & 2239 & & $1480(28.36)$ & 3739 (71.64) & 5219 & \\
\hline \multicolumn{9}{|l|}{ Current Marital Status } \\
\hline Living with husband & $794(15)$ & $4498(85)$ & 5292 & $* *$ & $2684(27.3)$ & $7149(72.7)$ & 9833 & $* * *$ \\
\hline Wid./div./sep. & $83(21)$ & $317(79.25)$ & 400 & & $260(38.2)$ & $421(61.8)$ & 681 & \\
\hline \multicolumn{9}{|l|}{ OCP Use } \\
\hline No & $642(15.5)$ & $3500(84.5)$ & 4142 & & $2249(29.2)$ & $5453(70.8)$ & 7702 & $* * *$ \\
\hline Yes & $235(15.16)$ & $1315(84.84)$ & 1550 & & $695(24.7)$ & $2117(75.3)$ & 2812 & \\
\hline \multicolumn{9}{|l|}{ Currently Working } \\
\hline No & $682(14.8)$ & $3928(85.2)$ & 4610 & $* *$ & $2621(27.9)$ & $6774(72.1)$ & 9395 & \\
\hline Yes & $195(18.02)$ & $887(81.98)$ & 1082 & & $323(28.9)$ & $796(71.1)$ & 1119 & \\
\hline \multicolumn{9}{|l|}{ Wealth Index } \\
\hline Poor & $269(33.2)$ & $542(66.8)$ & 811 & $* * *$ & $1755(35.3)$ & $3216(64.7)$ & 4971 & $* * *$ \\
\hline Middle & $121(19.9)$ & $486(80.1)$ & 607 & & $662(26.4)$ & $1846(73.6)$ & 2508 & \\
\hline Rich & $487(11.4)$ & $3787(88.6)$ & 4274 & & $527(17.36)$ & $2508(82.64)$ & 3035 & \\
\hline \multicolumn{9}{|c|}{ Exposure to Mass Media } \\
\hline No & $249(28.5)$ & $624(71.5)$ & 873 & $* * *$ & $1525(32.9)$ & $3109(67.1)$ & 4634 & $* * *$ \\
\hline Yes & $628(13.03)$ & $4191(86.97)$ & 4819 & & $1419(24.13)$ & $4461(75.87)$ & 5880 & \\
\hline \multicolumn{9}{|l|}{ Household Food Security } \\
\hline No & $344(23.3)$ & $1134(76.7)$ & 1478 & $* * *$ & $1382(33.7)$ & $2719(66.3)$ & 4101 & $* * *$ \\
\hline Yes & $533(12.65)$ & $3681(87.35)$ & 4214 & & $1562(24.36)$ & $4851(75.64)$ & 6413 & \\
\hline \multicolumn{9}{|l|}{ Genital Discharge } \\
\hline No & $748(14.6)$ & $4378(85.4)$ & 5126 & $* * *$ & $2516(26.82)$ & $6864(73.18)$ & 9380 & $* * *$ \\
\hline Yes & $129(22.79)$ & $437(72.21)$ & 566 & & $428(37.74)$ & $706(62.26)$ & 1134 & \\
\hline Total & $877(15.4)$ & $4815(84.6)$ & 5692 & & $2944(28.0)$ & 72.0 & 10514 & \\
\hline
\end{tabular}

Note: OCP refers to oral contraceptive pill; Wid./div./sep. refers to widowed/divorced/separated, Level of significance ${ }^{* * *} \mathrm{p}<0.001 ; * * \mathrm{p}<0.01 ; * \mathrm{p}<0.05$ ${ }^{1}$ Primary complete is defined as completing grade 5 .

${ }^{2}$ Secondary complete is defined as completing grade 10 .

\subsection{Determinants of Underweight}

Table 2 represented the estimate of binary logistic regression coefficients ( $\beta$ ), odds ratios (OR) and $95 \% \mathrm{CI}$ for OR. In the fitted models (Model 1 for urban area; Model II for rural area), out of nine predictors, seven factors for urban areas, and nine factors for rural areas were identified as statistically significant predictors of underweight. 
Table 2. Determinant factors of underweight of urban and rural ever-married non-pregnant women

\begin{tabular}{|c|c|c|c|c|}
\hline \multirow[t]{2}{*}{ Factors } & \multicolumn{2}{|c|}{ Urban } & \multicolumn{2}{|c|}{ Rural } \\
\hline & Co-efficient $(\beta)$ & OR $(95 \% \mathrm{CI})$ & Co-efficient $(\beta)$ & OR $(95 \% \mathrm{CI})$ \\
\hline \multicolumn{5}{|l|}{ Age (in years) } \\
\hline $15-24(r)$ & & 1.000 & & 1.000 \\
\hline $25-34$ & $-0.851 * * *$ & $0.427(0.348-0.525)$ & $-0.578 * * *$ & $0.561(0.495-0.636)$ \\
\hline $35-49$ & $-1.192 * * *$ & $0.304(0.238-0.387)$ & $-0.612 * * *$ & $0.542(0.470-0.625)$ \\
\hline \multicolumn{5}{|l|}{ Education } \\
\hline No education (r) & & 1.000 & & 1.000 \\
\hline Primary $^{1}$ & $-0.298 * *$ & $0.742(0.601-0.916)$ & -0.050 & $0.951(0.847-1.068)$ \\
\hline Secondary ${ }^{2}$ & $-0.537 * * *$ & $0.584(0.458-0.746)$ & $-0.148 *$ & $0.862(0.744-0.998)$ \\
\hline Higher & $-0.768 * * *$ & $0.464(0.307-0.700)$ & $-0.334^{*}$ & $0.716(0.513-0.999)$ \\
\hline \multicolumn{5}{|l|}{ Husbands education } \\
\hline No education (r) & & 1.000 & & 1.000 \\
\hline Primary $^{1}$ & -0.076 & $0.926(0.752-1.142)$ & $-0.145^{*}$ & $0.865(0.773-0.968)$ \\
\hline Secondary ${ }^{2}$ & $-0.259^{*}$ & $0.772(0.613-0.972)$ & $-0.210^{* *}$ & $0.811(0.710-0.925)$ \\
\hline Higher & $-0.569 * *$ & $0.566(0.404-0.793)$ & $-0.549 * * *$ & $0.578(0.458-0.729)$ \\
\hline \multicolumn{5}{|l|}{ Child Ever Born } \\
\hline No child (r) & & 1.000 & & 1.000 \\
\hline $1-2$ child & -0.125 & $0.882(0.677-1.150)$ & $-0.222 *$ & $0.801(0.674-0.952)$ \\
\hline$>2$ children & 0.090 & $1.094(0.799-1.497)$ & -0.091 & $0.913(0.754-1.106)$ \\
\hline \multicolumn{5}{|l|}{ OCP Use } \\
\hline No (r) & & 1.000 & & 1.000 \\
\hline Yes & -0.066 & $0.936(0.786-1.114)$ & $-0.207 * * *$ & $0.813(0.733-0.902)$ \\
\hline \multicolumn{5}{|l|}{ Wealth Index } \\
\hline Poor (r) & & 1.000 & & 1.000 \\
\hline Middle & $-0.458^{* *}$ & $0.632(0.489-0.819)$ & $-0.238 * * *$ & $0.788(0.703-0.884)$ \\
\hline Rich & $-0.666^{* * *}$ & $0.514(0.415-0.636)$ & $-0.587 * * *$ & $0.556(0.485-0.637)$ \\
\hline \multicolumn{5}{|l|}{ Mass Media Exposure } \\
\hline No (r) & & 1.000 & & 1.000 \\
\hline Yes & $-0.382 * * *$ & $0.683(0.559-0.834)$ & $-0.136^{* *}$ & $0.873(0.791-0.963)$ \\
\hline \multicolumn{5}{|c|}{ Household Food Security } \\
\hline No (r) & & 1.000 & & 1.000 \\
\hline Yes & $-0.211^{*}$ & $0.810(0.681-0.963)$ & $-0.180 * * *$ & $0.836(0.760-0.919)$ \\
\hline \multicolumn{5}{|l|}{ Genital Discharge } \\
\hline No (r) & & 1.000 & & 1.000 \\
\hline Yes & $0.462 * * *$ & $1.588(1.273-1.981)$ & $0.234^{* *}$ & $1.264(1.105-1.446)$ \\
\hline
\end{tabular}

Note: 'OCP' refers to oral contraceptive pill; ' $r$ ' indicates reference category; 'OR' indicates odds ratio; 'Cl' indicates confidence interval; Level of significance $* * * \mathrm{p}<0.001 ; * * \mathrm{p}<0.01 ; * \mathrm{p}<0.05$

${ }^{1}$ Primary complete is defined as completing grade 5 .

${ }^{2}$ Secondary complete is defined as completing grade 10 .

The result depicted that, age was one of the significant determinants of underweight among the respondents. Urban women aged 25-34 years and 35-49 years were 0.427 times (OR: $0.427,95 \%$ CI: $0.348-0.525$ ) and 0.304 times (OR: $0.304,95 \%$ CI: $0.238-0.387$ ) lower risk to have underweight as compared to the women aged 15-24 years respectively. On the other hand, rural women aged 25-34 years and 35-49 years have 0.561 times (OR: $0.561,95 \%$ CI: $0.495-0.636$ ) and 0.542 times (OR: $0.542,95 \%$ CI: $0.470-0.625$ ) lower risk to be underweight compared to the women aged 15-24 years respectively.

Respondent's education was another significant determinant of underweight. Higher educated urban women were 0.464 times (OR: 0.464 , 95\% CI: 0.307-0.700) less likely to have underweight as compared to their illiterate counterpart; whereas in rural areas, women with secondary and higher education were found 0.862 times (OR: 0.862 , 95\% CI: 0.744-0.998) and 0.716 times (OR: $0.716,95 \%$ CI: 0.513-0.999) less chance to be underweight compared to their illiterate counterpart.

Considering no education as the reference category, the results indicated that, urban women whose husbands were secondary and higher educated have 0.772 times (OR: 0.772 , 95\% CI: $0.613-0.972$ ) and 0.566 times (OR: $0.566,95 \%$ CI: 
0.404-0.793) lower risk of having underweight respectively. On the contrary, rural women whose husbands were secondary and higher educated have 0.881 times (OR: 0.881 , 95\% CI: $0.710-0.925$ ) and 0.578 times (OR: $0.578,95 \%$ CI: 0.458-0.729) lower risk to be underweight compared to illiterate husband respectively. The CEB also appeared as a significant determinant of underweight among rural women. Rural women who have 1-2 children have 0.801 times (OR: $0.801,95 \%$ CI: 0.674-0.952) lower risk of becoming underweighted compared to those women having no child.

For rural women, OCP use has significant effects on underweight and the women who use OCP have 0.813 times (OR: 0.813 , 95\% CI: $0.733-0.902$ ) less chance of having underweight compared to those do not use OCP. Urban middle class and rich women were 0.632 times (OR: 0.632, 95\% CI: $0.489-0.819$ ) and 0.514 times (OR: $0.514,95 \%$ CI: $0.415-0.636$ ) less likely to have underweight than their poor counterpart respectively. On the other hand, rural middle class and rich women have 0.788 times (OR: $0.788,95 \%$ CI: $0.703-0.884$ ) and 0.556 times (OR: $0.556,95 \%$ CI: $0.485-0.637$ ) less risk to be underweight as compared to their poor counterpart. The exposure to mass media was a significant predictor for the urban and rural areas women. The women in the urban and rural areas having 0.683 times (OR: 0.683 , 95\% CI: $0.559-0.834$ ) and 0.873 times (OR: $0.873,95 \%$ CI: $0.791-0.963)$ respectively less likely to be underweight compared to the women who did not have access to mass media. Women from food secured households have 0.836 times (OR: $0.836,95 \%$ CI: $0.770-0.909$ ) lower probability of having underweight than women from food unsecured households. The corresponding odds for urban and rural women were 0.810 (OR: $0.810,95 \%$ CI: $0.681-0.963$ ) and 0.836 (OR: $0.836,95 \%$ CI: $0.760-0.919$ ) respectively. Genital discharge of women also shows significant effect on underweight. Urban women who had genital discharge in last 12 months have 1.588 times (OR: $1.588,95 \%$ CI: $1.273-1.981)$ more risk to be underweight than those had no genital discharge, whereas among rural women who had genital discharge in last 12 months, the chance is 1.264 times (OR: $1.264,95 \%$ CI:1.105-1.446) more compared to those who had no genital discharge.

\section{Discussion}

The present study demonstrated a clear difference in the prevalence of underweight between urban and rural women of Bangladesh. While observing from different socioeconomic and demographic perspectives, the present study showed that, the prevalence of underweight was always higher among rural women than that of urban women. The results revealed that the prevalence of being underweight is gradually decreasing among ever-married women in Bangladesh. The under weightiness among ever-married women has decreased from $34 \%$ to $24 \%$ from BDHS 2004 to BDHS 20111. But, the overall prevalence of being underweight among rural women is around two times more than that of urban women (28\% rural, $15.4 \%$ urban). Our study results are found consistent with the results of the other studies [25-27].

Age was found significantly associated with underweight among women in Bangladesh. The present study found the higher prevalence of underweight among young women (aged 14-24 years) and it decreased as age increased, which was similar with the findings of other studies conducted in Bangladesh [26-27] and India [28].

Among urban and rural women of Bangladesh, the lower educational level represented the higher prevalence of underweight. The finding of the present study was similar with the findings of other studies conducted in Bangladesh [25-27], Ethiopia [29], India [28, 30-31] and Sub-Saharan African countries [7, 32-33]. This is because educated women were more conscious about their diet, food habit, personal hygiene, were able to take independent decisions [34], and have had greater access to household resources. In the reproductive aged women of Bangladesh it was observed that, education level was positively related to the better nutritional status [34]. Like women's education, educational level of their husband is also associated with their nutritional status. The findings show higher prevalence of underweight among women with illiterate husbands. The CEB was found as a significant determinant factor of underweight of the respondents and it was more prevalent among the women who have no child. This finding supported the results of the previous studies [25, 34]. OCP use reduced the vulnerability of women to underweight, which is also consistent with other studies $[25,35]$. The study results revealed that, widowed, divorced or separated women were found more underweighted than that of married women, which is similar with the findings of the studies [25-27]. The currently working women were found more underweight in both the areas, which were found consistent with the studies [26, 28, 34]. Wealth index showed an inverse relation with underweight. There was a strong association between poor socio-economic condition and underweight. This study noticed that, the prevalence of underweight decreased as with the increased of economic status. Because of poor people cannot buy expensive nutritious food items like meat, milk, fruits regularly. Several recent studies in Bangladesh [25-27, 34-35] and worldwide [14, 15, 36] also found the similar results. Importantly, national income contributed to increase literacy rate, dietary food intake, preserve food, etc. which consequently increase life expectancy [37-39].

The study results confirmed that, women who have had accession in mass media (reading newspaper, watching television or listening radio) were comparatively less underweighted. A study in Bangladesh found lower prevalence of underweight among women who watch television and read newspaper or magazine daily [27]. Food insecurity is common among the poor households in many developing countries which contributed to nutritional disorder and poor health among the household members [40]. It is found associated with lower macro- and micro-nutrient intakes, lower intake of fruits and vegetables, 
and lack of diet diversity which contribute to higher prevalence of underweight [40] and can affect health either directly or indirectly through under nutrition [41]. The study obtained higher prevalence of underweight among women of food unsecured household. Similar result was reported by another study in Trinidad [42], where authors found significant association of food insecurity with underweight. Women who had genital discharge in last one year were more undernourished; because, vaginal or genital discharge makes women more suspicious to underweight.

\section{Conclusions}

The under weightiness among non-pregnant ever-married women for both urban and rural areas were found prevalent. This study identified strong urban-rural differentials in the prevalence of under weightiness among ever-married non-pregnant women. Respondents' lower age, less or lower education, husbands' less or lower education, low income status, less access to mass media, household food insecurity, and genital discharge are identified as the determinant factors of underweight. Special nutritional program should be provided substantially for reducing underweight in the age group 15-24 years. Public health interventions are clearly needed to reduce the prevalence of underweight among rural women in Bangladesh. Awareness programs about the consequences of underweight including prevention activities should be provided in the schools, the work place and the community. Systematic monitoring and surveillance of nutritional status especially in the rural areas are also important to address the problem of underweight. More research is needed.

\section{Acknowledgements}

The authors are enormously grateful to Mitra and Associates, NIPORT, MOHFW, Government of Bangladesh; and Macro International, USA; for giving permission to use their database. The authors are thankful to the Department of Population Science and Human Resource Development, University of Rajshahi, Bangladesh for granting supports to complete this study. Thanks are also to the editor and the referees for their comments and criticism, which lead to greatly improved version of this paper.

\section{Conflict of Interests}

The authors declare that they have no competing interests.

\section{Funding}

The authors received no financial support for the research, authorship, and/or publication of this article.

\section{REFERENCES}

[1] Doak CM, Adair LS, Bentley M, Monteiro C, Popkin BM. The dual burden household and the nutrition transition paradox. Int J Obes (Lond) 2005; 29:129-36.

[2] Jafar TH, Chaturvedi N, Pappas G. Prevalence of overweight and obesity and their association with hypertension and diabetes mellitus in an Indo-Asian population. CMAJ, 2006; 175:1071-77.

[3] Flegal KM, Graubard BI, Williamson DF, Gail MH. Excess deaths associated with underweight, overweight, and obesity. JAMA 2005; 293:1861-67.

[4] Woodward M, Reid MA. Cardiovascular disease in the Asia-Pacific region: challenges for health research and policy. Med J Aust 2003; 179:71-72.

[5] Caballero B. The global epidemic of obesity: an overview. Epidemiol Rev., 2007; 29:1-5.

[6] Shafique S, Akhter N, Stallkamp G, de Pee S, Panagides D, Bloem MW. Trends of under-and overweight among rural and urban poor women indicate the double burden of malnutrition in Bangladesh. Int J Epidemiol 2007; 36:449-57.

[7] Mendez MA, Monteiro CA, Popkin BM. Overweight exceeds underweight among women in most developing countries. Am J Clin Nutr 2005; 81:714-21.

[8] Caulfield LE, de Onis Ms, Blössner M, and Black R E. Under nutrition as an underlying cause of child deaths associated with diarrhea, pneumonia, malaria, and measles. Am J Clin Nutr 2004; 80:193-98.

[9] Ehrenberg HM, Dierker L, Milluzzi C, Mercer BM. Low maternal weight, failure to thrive in pregnancy, and adverse pregnancy outcomes. Am J Obstet Gynecol 2003; 189:1726-30.

[10] Rayhan MI, Khan MSH. Factors causing malnutrition among under five children in Bangladesh. Pakistan J Nutr 2006; 5(6):558-62.

[11] Ali, S. M. \& Lindstrom, M. Socioeconomic, psychosocial, behavioral, and psychological determinants of BMI among young women: differing patterns for underweight and overweight/obesity. European Journal of Public Health2006; 16(3), 324-30.

[12] Visscher TLS, Seidell JC, Menotti A, et al. Underweight and overweight in relation to mortality among men aged 40-59 and 50-69 years: The Seven Countries Study. Am J Epidemiol 2000; 151:660-66.

[13] Doak CM, Adair LS, Monteiro C, Popkin BM. Overweight and underweight coexist within households in Brazil, China and Russia. J Nutr 2000; 130:2965-71.

[14] Pryer JA, Rogers S. Epidemiology of under nutrition in adults in Dhaka slum households, Bangladesh. Eur J Clin Nutr 2006; 60:815-22.

[15] Pryer JA, Rogers S, Rahman A. Factors affecting nutritional status of female adults in Dhaka slums, Bangladesh. Soc Biol 2003; 50:259-69. 
[16] Fryar CD, Ogden CL. Prevalence of Underweight among Adults Aged 20 and Over: United States, 1960-1962 through 2007-2010. CDC, Division of Health and Nutrition Examination Surveys. September 2012.

[17] Shaikh S, Mahalanabis D, Chatterjee S, Kurpad AV, Khaled MA. Lean body mass in preschool aged urban children in India: gender difference. Eur J Clin Nutr 2003; 57:389-93.

[18] Hossain MK, Mondal MNI, Akter MN. Reproductive health rights of women in the rural areas of Meherpur district in Bangladesh. J Reprod Infertil 2011; 12(1):23-32.

[19] Farouk SA. Violence against women: A statistical overview, challenges and gaps in data collection and methodology and approaches for overcoming them. United Nations' Division for the Advancement of Women, 2005; Geneva, Switzerland.

[20] Subramanian SV, Perkins JM, Khan KT. Do burdens of underweight and overweight coexist among lower socioeconomic groups in India? Am J Clin Nutr 2009; 90:369-76.

[21] Mondal MNI, Hossain MK, Ali MK. Factors influencing infant and child mortality: A case study of Rajshahi district, Bangladesh. J Hum Ecol 2009; 26(1):31-39.

[22] Rahman A, Chowdhury S. Determinants of chronic malnutrition among preschool children in Bangladesh. J Biosoc Sci 2007; 39:161-73.

[23] NIPORT. Bangladesh Demographic and Health Survey 2011. National Institute of Population Research and Training (NIPORT), Mitra and Associates \& Macro International. Dhaka, Bangladesh and Calverton, Maryland, USA, 2013.

[24] WHO Expert Consultation. Appropriate body mass index for Asian populations and its implications for policy and intervention strategies. Lancet, 2004; 363(9403):157-63.

[25] Corsi DJ, Kyu HH, Subramanian, S V. Socioeconomic and geographic patterning of underweight and overweight among women in Bangladesh. The Journal of Nutrition, 2011; 141, 631-38.

[26] Kamal SMM, Islam M A. Socio-economic correlates of malnutrition among married women in Bangladesh. Malaysian Journal of Nutrition 2010; 16(3), 349-59.

[27] Khan MMH, Kramer A. Factors associated with being underweight, overweight and obese among ever-married non-pregnant urban women in Bangladesh. Singapore Medical Journal 2009; 50(8), 804-13.

[28] Subramanian SV, Smith GD. Patterns, distribution, and determinants of under- and over nutrition: a population-based study of women in India. American Journal of Clinical Nutrition, 2006; 84, 633- 40.

[29] Teller H, Yimar G. Levels and determinants of malnutrition in adolescent and adult women in Southern Ethiopia. Ethiopian
Journal of Health Development, 2000; 14(1), 57-66.

[30] Naidu AN, and Rao NP. Body Mass Index: A Measure of the Nutritional Status in Indian Populations. European Journal of Clinical Nutrition 1994; 48:s131-s140.

[31] Shankar H, Dabral SB, Walia DK. Nutritional status of newly married women (married last 2 years from date of survey) in rural area of Allahabad, India. Indian J. Prev. Soc. Med, 2010; 4:192-97.

[32] Caballero B, Rubinstein S. Environmental factors affecting nutritional status in urban areas of developing countries. Arch Latinoam Nutr 1997; 47(2 suppl 1):3-8.

[33] Rosenberg LL, Palmer JR, Wise LA, Horton NJ, Kumanyika SK, Adams-Campbell LL. prospective study of the effect of childbearing on weight gain in African American women. Obes Res 2003; 11:1526-35.

[34] Rahman MM, Nasrin SO. Mothers nutritional status in an impoverished nation: Evidence from rural Bangladesh. The Internet Journal of Nutrition and Wellness 2009; 7(1).

[35] Milton AH, Smith W, Rahman B, Ahmed B, Shahidullah S M, Hossain Z, Hasan Z, Sharmin S. Prevalence and determinants of malnutrition among reproductive aged women of rural Bangladesh. Asia Pacific Journal of Clinical Nutrition, 2010; 22(1):110-17.

[36] Clausen T, Charlton KE, Holmboe-Ottesen G. Nutritional status, tobacco use and alcohol consumption of older persons in Botswana. The Journal of Nutrition Health and Aging, 2006; 10:104-10.

[37] Mondal MNI, Shitan M. Relative Importance of Demographic, Socioeconomic and Health Factors on Life Expectancy in Low- and Lower-Middle-Income Countries. J Epidemol 2014;24(2):117-24.

[38] Mondal MNI, Shitan M. Factors affecting the HIV/AIDS epidemic: an ecological analysis of global data. African Health Sciences 2013;13(2):301-10.

[39] Mondal MNI, Shitan M. Imapact of Socio-Health Factors on Life Expectancy in the Low and Lower Middle Income Countries. Iranian J Publ Health 2013;42(12):1354-62.

[40] Mohamadpour M, Sharif ZM, Keysami MA. Food insecurity, health and nutritional status among sample of palm-plantation households in Malaysia. J Health Popul Nutr. 2012 Sep; 30(3):291-302.

[41] Campbell CC. Food insecurity: a nutritional outcome or a predictor variable? Journal of Nutrition 1991; 121:408-15.

[42] Ramdath DD, Hilaire DG, Cheong KD, Sharma S. Dietary intake among adults in Trinidad and Tobago and development of a quantitative food frequency questionnaire to highlight nutritional needs for lifestyle interventions. Int J Food Sci Nutr. 2011 Sep; 62(6):636-41. 